\title{
Epidural fentanyl and Caesarean section: when should fentanyl be given?
}

\begin{abstract}
Epidural fentanyl is often added to epidural local anaesthetic agents to improve the quality of anaesthesia obtained during Caesarean section. Fentanyl may be given either before or after delivery of the infant. When given before delivery, fentanyl has not been reported to cause neonatal depression, although this remains a concern. A prospective, randomized, double-blind study was undertaken to determine if fentanyl was more effective if given before or after delivery of the baby in 64 women undergoing Caesarean section under lidocaine epidural anaesthesia. Maternal outcome was determined by time to achieve $T_{4}$ neural blockade, the dose of lidocaine necessary to achieve this block and intraoperative scores for pain, nausea, vomiting, shivering, and sedation. Neonates were assessed by umbilical arterial blood $\mathrm{pH}$ and Apgar scores. No differences were detected in either group with respect to maternal or neonatal outcome. We recommend using only epidural local anaesthetic agents before delivery, and giving epidural fentanyl following delivery of the infant.
\end{abstract}

Le fentanyl est souvent ajouté aux agents anesthésiques locaux administrés par voie épidurale afin d'améliorer la qualité de l'anesthésie au cours d'une césarienne. Le fentanyl peut être administré avant ou après la naissance. Une étude prospective, à double insu, avec distribution aléatoire, a été faite chez 64 parturientes qui ont accouché par césarienne sous anesthésie épidurale. Le but était de déterminer si le fentanyl était plus

\section{Key words}

ANAESTHESIA: obstetrical;

ANAESTHETIC TECHNIQUES: epidural;

ANALGESICS: fentanyl.

From the Department of Anaesthesia, Foothills Hospital at the University of Calgary, Calgary, Alberta.

Presented in part at the 48th Annual Meeting of the Canadian Anaesthetists' Society, Quebec City, Quebec, June 24, 1991.

Address correspondence to: Dr. J.A. Janzen, Department of Anaesthesia, Foothills Hospital, 140329 St. N.W., Calgary, Alberta T2N 2T9.

Accepted for publication 28th December, 1991. efficace lorsque donné avant la naissance. Les paramètres évalués chez la mère étaient le temps requis pour atteindre un bloc sensitif au niveau de $T_{4}$, la dose de lidocaïne nécessaire pour atteindre ce niveau d'anesthésie, la douleur peropératoire, le degré de sédation, ainsi que l'incidence de frissons, nausées et vomissements. L'Apgar et le $\mathrm{pH}$ du sang artériel ombilical ont été évalués chez les nouveau-nés. Aucune différence significative n'a été trouvée entre les groupes pour chacun des paramètres évalués chez les mères et les nouveaunés. Nous recommandons d'administrer seulement l'agent anesthésique local par voie épidurale avant l'accouchement et de donner le fentanyl après la naissance.

The use of epidural opioids in obstetrical anaesthesia occurred soon after the discovery of opioid receptors in the central nervous system. Epidural narcotics were found to provide analgesia in labour, although the analgesia was often inadequate. 'Epidural narcotics were then examined as an adjunct to local anaesthetic agents to improve the quality of anaesthesia in women undergoing Caesarean section under epidural anaesthesia. ${ }^{2-6}$ Epidural fentanyl given after delivery of the baby was shown to provide better intraoperative anaesthesia for the mother than epidural bupivacaine alone. ${ }^{2}$ Subsequent investigators compared giving lidocaine and fentanyl together with lidocaine alone, ${ }^{5}$ and bupivacaine and fentanyl with bupivacaine alone. ${ }^{3,4,6}$ Fentanyl was shown to improve the quality of the anaesthesia by decreasing intraoperative pain scores. Epidural fentanyl can stop established shivering caused by epidural anaesthesia, ${ }^{7}$ and decrease nausea and vomiting during exteriorization of the uterus. ${ }^{8}$ Fentanyl has not been reported to cause neonatal depression beyond that caused by local anaesthetics themselves, although this remains a concern. This study compared neonatal and maternal outcomes in women having Caesarean sections under epidural lidocaine anaesthesia with epidural fentanyl given before or after delivery of the infant.

\section{Methods}

A prospective, randomized, double-blind study protocol was designed and approved by the hospital ethics commit- 
tee. Informed consent was obtained from 64 patients having elective Caesarean sections under epidural anaesthesia. All patients were ASA classification I or II, 18 or more years of age, single gestation, and gestational age of at least $36 \mathrm{wk}$. A nurse who was not involved in the study placed fentanyl $1.5 \mathrm{ml}(75 \mu \mathrm{g})$ or preservative-free normal saline $1.5 \mathrm{ml}$ into syringes labelled " $A$ " and " $B$ " according to the randomization protocol.

All inpatients received ranitidine $150 \mathrm{mg}$ po the evening before operation, and two hours before surgery. All patients (inpatients and patients admitted on the day of surgery) received $30 \mathrm{ml}$ sodium citrate $0.3 \mathrm{M}$ on call to the operating room. A large bore iv catheter was inserted and patients were given two litres of lactated Ringer's solution at room temperature. Epidural catheters were inserted at the $\mathrm{L}_{2-3}$ interspace when possible, otherwise at the $\mathrm{L}_{3-4}$ interspace. Each catheter was advanced $3-4 \mathrm{~cm}$ in a cephalad direction. Patients were then placed supine with $15^{\circ}$ left uterine displacement. All patients received oxygen, five litres per minute, by mask, until delivery. Epidural anaesthesia was induced with lidocaine $2 \%$ with epinephrine 1:200,000 freshly added (all subsequent references to "lidocaine" mean lidocaine $2 \%$ with epinephrine 1:200,000 added). A test dose of $3 \mathrm{ml}$ lidocaine was given. If no signs of intravascular or intrathecal injection were apparent, the patient received study drug "A" $1.5 \mathrm{ml}$, followed immediately by $3 \mathrm{ml}$ lidocaine. A further $3 \mathrm{ml}$ lidocaine was given every three minutes until a $\mathrm{T}_{4}$ block was obtained or a dose of $7 \mathrm{mg} \cdot \mathrm{kg}^{-1}$ was reached. Block height was measured by loss of cold sensation to ice. Hypotension (defined as a decrease in systolic blood pressure (SBP) below $100 \mathrm{mmHg}$ ) was treated with ephedrine $5 \mathrm{mg}$ as needed. After delivery of the infant, syringe " $B$ " was diluted to a $10 \mathrm{ml}$ volume with preservative-free normal saline and given as a bolus via the epidural catheter. Oxytocin $20 \mathrm{u} \cdot \mathrm{l}^{-1}$ in lactated Ringer's solution was begun. Bolus doses of oxytocin were not administered. Patients received $10-20 \mathrm{u}$ of oxytocin during abdominal closure. The patients who received fentanyl in syringe "A" were designated Group I, and those who received saline in syringe " $A$ " (fentanyl in syringe " $B$ ") were designated Group II.

Maternal outcome was measured by: (1) the time needed to achieve a $\mathrm{T}_{4}$ block, (2) the dose of lidocaine required, and (3) the intraoperative variables pain, shivering, nausea, vomiting, and sedation. Data concerning the variables were obtained at skin incision, bladder retraction, uterine incision, uterine exteriorization (if performed), peritoneal closure, and skin closure. The scoring systems are outlined in Table I. Maternal tympanic membrane temperature was measured before insertion of the iv catheter and at the end of the Caesarean section.

Moderate to severe pain was treated initially with inha-
TABLE I Scoring systems for maternal symptoms during Caesarean section

\begin{tabular}{|c|c|c|c|c|}
\hline \multirow[b]{2}{*}{ Variable } & \multicolumn{4}{|l|}{ Score } \\
\hline & 0 & 1 & 2 & 3 \\
\hline Pain & None & Mild & Moderate & Severe \\
\hline $\begin{array}{l}\text { Nausea } \pm \\
\text { vomiting }\end{array}$ & None & $\begin{array}{l}\text { Mild } \\
\text { nausea }\end{array}$ & $\begin{array}{l}\text { Severe } \\
\text { nausea }\end{array}$ & Vomiting \\
\hline Sedation & Awake & Drowsy & Asleep & \\
\hline Shivering & None & Mild & $\begin{array}{c}\text { Moderate } \\
\text { and dis- } \\
\text { tressing }\end{array}$ & $\begin{array}{l}\text { Severe, } \\
\text { distressing } \\
\text { and inter- } \\
\text { feres with } \\
\text { monitoring }\end{array}$ \\
\hline
\end{tabular}

TABLE II Demographic information (mean \pm SD)

\begin{tabular}{lcc}
\hline & Group I & Group II \\
\hline Age (yr) & $29.6 \pm 4.0$ & $32.2 \pm 4.6$ \\
Weight $(\mathrm{kg})$ & $77.3 \pm 9.3$ & $75.5 \pm 12.2$ \\
Height $(\mathrm{cm})$ & $165 \pm 5.5$ & $162 \pm 6.6$ \\
Gest age $(\mathrm{wk})^{*}$ & $38.8 \pm 1.0$ & $38.9 \pm 1.3$ \\
\hline
\end{tabular}

${ }^{*}$ Gest age $=$ gestational age

lation of 50:50 nitrous oxide and oxygen. Persistent pain before delivery was treated with ketamine $0.25 \mathrm{mg} \cdot \mathrm{kg}^{-1}$ $i v$ to a maximum of $0.5 \mathrm{mg} \cdot \mathrm{kg}^{-1}$. Pain after delivery that was unrelieved by nitrous oxide and oxygen was treated with fentanyl $50 \mu \mathrm{g} i v$ to a maximum of $100 \mu \mathrm{g}$. Severe nausea or vomiting was treated with metoclopramide 10 $\mathrm{mg} i v$.

Neonatal outcome was determined by: (1) Apgar scores at one and five minutes, (2) umbilical arterial blood $\mathrm{pH}$, and (3) umbilical venous plasma fentanyl concentrations. Following delivery of the placenta, $10 \mathrm{ml}$ of venous cord blood was taken and centrifuged at $8,500 \mathrm{rpm}$ for $20 \mathrm{~min}$. The plasma was removed and frozen at $-20^{\circ} \mathrm{C}$ until study completion. All samples were then analyzed for fentanyl by high resolution gas chromatography. The sensitivity of this assay was $0.1 \mathrm{ng} \cdot \mathrm{ml}^{-1}$ with a coefficient of variation of $8 \%$ between samples.

Power analysis was performed before the study to determine the number of patients needed. Based on our experience and the literature, we assumed that $75 \%$ of patients not receiving epidural fentanyl would have adequate analgesia (not require supplementation). We assumed that 95\% of patients receiving fentanyl would not require supplemental medication. Setting $\alpha=0.05$ and $\beta=0.80$, it was calculated that 28 patients would be needed in each group. This was rounded up to 30 patients per group. Data analysis consisted of the unpaired Student's $t$ test for parametric data, and for nonparametric data the Chi- 
TABLE III Time to epidural blockade and dose of $2 \%$ lidocaine needed (mean $\pm \mathrm{SD})$

\begin{tabular}{lrrr}
\hline & Group I & Group II & P \\
\hline $\mathrm{T}_{4}(\min )$ & $17.1 \pm 5.2$ & $15.2 \pm 3.4$ & NS \\
$\mathrm{S}_{2}(\mathrm{~min})$ & $13.5 \pm 2.5$ & $14.1 \pm 3.3$ & $\mathrm{NS}$ \\
Lido $(\mathrm{ml})$ & $17.8 \pm 5.0$ & $15.8 \pm 3.4$ & $\mathrm{NS}$ \\
Lido $\left(\mathrm{mg} \cdot \mathrm{kg}^{-1}\right)$ & $4.7 \pm 1.4$ & $4.3 \pm 1.1$ & $\mathrm{NS}$ \\
\hline
\end{tabular}

$\mathrm{T}_{4}=$ time to $\mathrm{T}_{4}$ level block, $\mathrm{S}_{2}=$ time to $\mathrm{S}_{2}$ level block, Lido = dose of lidocaine $2 \%$ with 1:200,000 epinephrine added.

TABLE IV Number of patients receiving supplemental medication

\begin{tabular}{llll}
\hline & Group I & Group II & $P$ \\
\hline $\mathrm{N}_{2}$ O before delivery & 1 & 3 & NS \\
$\mathrm{N}_{2}$ O after delivery & 2 & 4 & NS \\
Ketamine & 1 & 3 & NS \\
Fentanyl & 0 & 4 & NS \\
\hline
\end{tabular}

squared statistic or the Mann-Whitney rank sum test where appropriate. Statistical significance was inferred for $P<0.05$.

\section{Results}

Sixty-four patients were enrolled in the study. Four patients were withdrawn leaving 30 patients in each group. The reasons for withdrawal were: (1) inadvertent dural puncture, (2) inability to place an epidural catheter, (3) insufficient block despite reaching the maximum dose of lidocaine $\left(7 \mathrm{mg} \cdot \mathrm{kg}^{-1}\right)$, and (4) unusual block $\left(\mathrm{T}_{4}\right.$ on the right side, $T_{10}$ on the left) with reluctance to continue giving lidocaine every three minutes as per protocol.

Demographic information showed the two groups were similar with respect to age, height, weight, and gestational age (Table II). All epidural catheters were placed at $\mathrm{L}_{2-3}$ in Group II, whereas in Group I, 24 were placed at $\mathrm{L}_{2-3}$ and six at $\mathrm{L}_{3-4}(P<0.05)$. The times to onset of $\mathrm{T}_{4}$ and $\mathrm{S}_{2}$ blockade were similar between groups as were the doses of lidocaine used (Table III). Fifteen patients (25\%) required only $12 \mathrm{ml}$ of lidocaine to establish a $\mathrm{T}_{4}$ level block, seven in Group I and eight in Group II. Six patients in Group I and four in Group II required ephedrine for SBP $<100 \mathrm{mmHg}$.

Pain scores at skin incision, bladder retraction, uterine incision, uterine exteriorization (if performed), peritoneal closure, and skin closure are shown in Figure 1. Comparison between groups revealed no difference in pain scores before or after delivery (Figure 2). No patient required induction of general anaesthesia.

Nitrous oxide was used by one patient in Group I before delivery and by two patients after delivery (Table IV). In Group II, three patients used nitrous oxide before delivery and four after. There was no statistical difference between

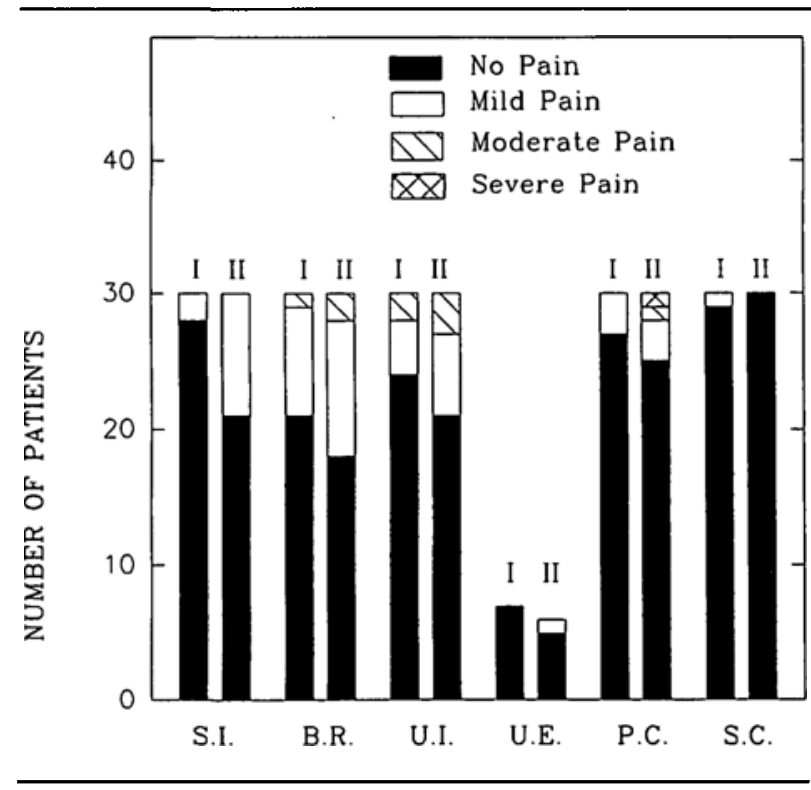

FIGURE 1 Pain scores during Caesarean sections. I = Group I; II = Group II; S.I. = skin incision; U.I. = uterine incision; P.C. = peritoneal closure; B.R. = bladder retraction; U.E. = uterine exteriorization; S.C. $=$ skin closure.

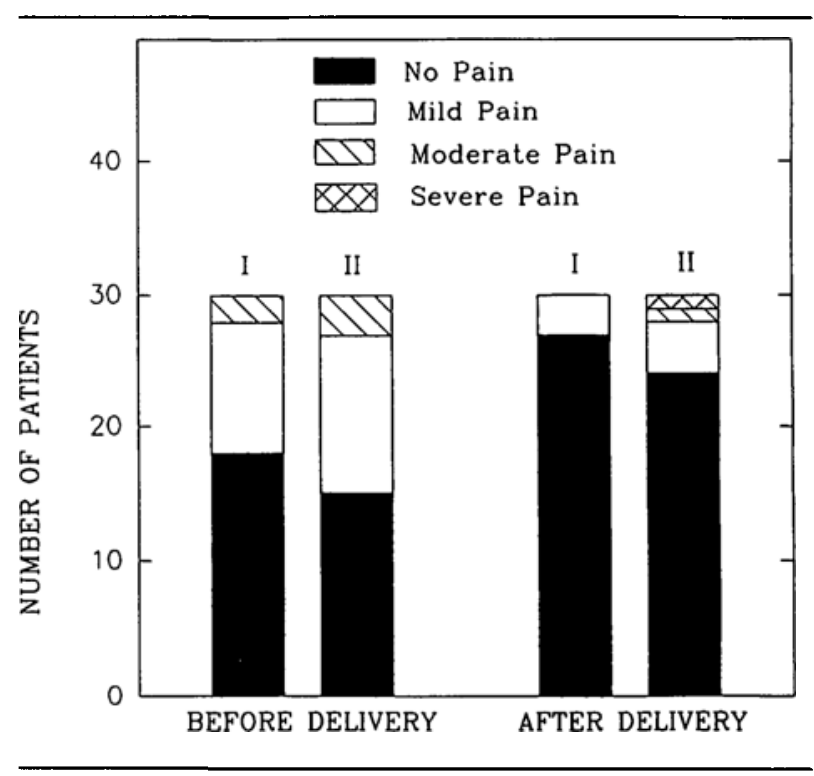

FIGURE 2 Maternal pain scores before and after delivery. I = Group I; II = Group II.

groups. Ketamine was required for one patient in Group I and three patients in Group II. No patient received fentanyl $i v$ in Group I, compared with four patients in Group II. The use of ketamine and fentanyl was not different between groups.

Sedation, nausea and/or vomiting, shivering, and chest pain were experienced with similar frequencies in both 


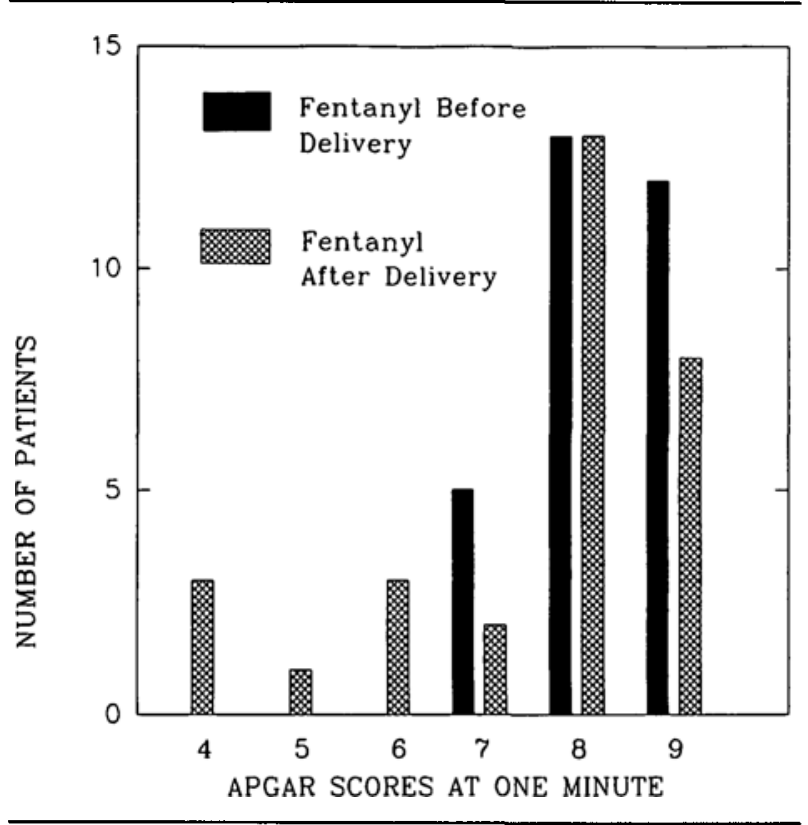

FIGURE 3 Apgar scores at one minute.

groups (Table V). The differences were not statistically different. In the subgroup having uterine exteriorization (12 patients), nausea occurred in one of seven patients in Group I, and in one in five patients in Group II before delivery. After delivery two of seven women in Group I and one of five in Group II experienced nausea. No patient vomited during uterine exteriorization. Of the patients who experienced shivering, the temperature decreased $0.50 \pm$ $0.45^{\circ} \mathrm{C}$ compared with $0.67 \pm 0.45^{\circ} \mathrm{C}$ in those who did not experience shivering (NS). Twenty-six of the 60 patients ( $43 \%$ ) shivered at some time during the operation.

Umbilical arterial blood $\mathrm{pH}$ measurements were $7.31 \pm$ 0.03 in Group I and $7.31 \pm 0.03$ in Group II. No differences were determined in the one and five-minute Apgar scores (Figures 3 and 4). The lowest one-minute Apgar score in Group I was seven whereas there were three scores of four in Group II. All Apgar scores in both groups were eight or higher by five minutes. The uterine incision to delivery (UID) times, expressed as mean \pm SD, were $76.4 \pm 25.3 \mathrm{sec}$ for Group I, and $90.6 \pm 40.7 \mathrm{sec}$ for Group II. The UID times were not prolonged in those infants having low one-minute Apgar scores (Table VI).

Umbilical venous plasma fentanyl was detectable in many patients but an interfering peak precluded accurate determination of plasma fentanyl concentrations. Several attempts to separate the masking peak were unsuccessful. Thus, no umbilical venous plasma fentanyl concentrations are reported.

\section{Discussion}

This study failed to show any benefit of adding fentanyl 75

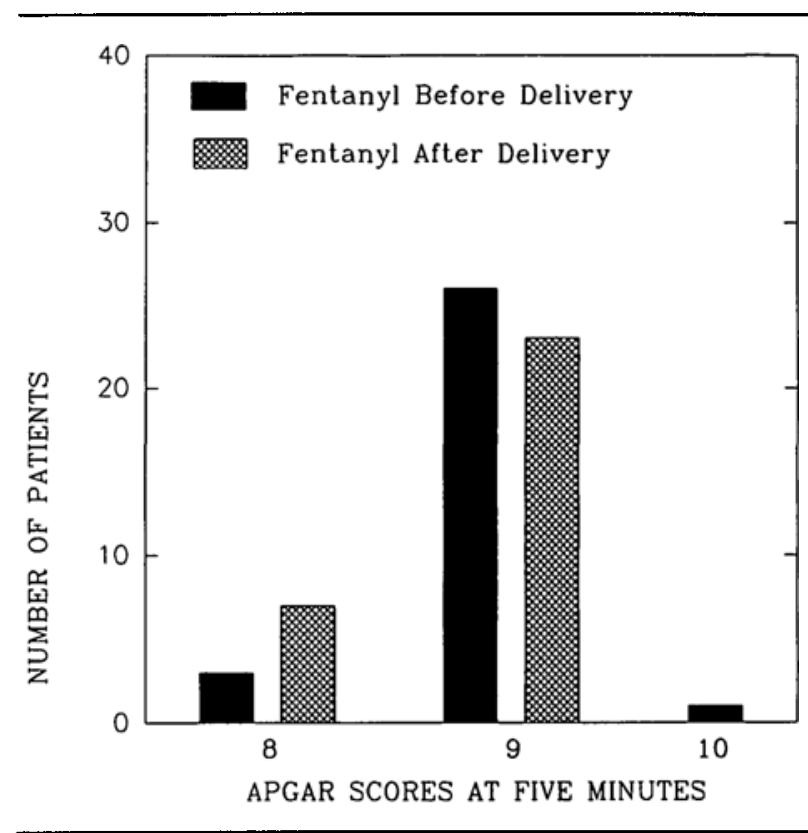

FIGURE 4 Apgar scores at five minutes.

TABLE $\vee$ Number of patients having symptoms during Caesarean section

\begin{tabular}{lccc}
\hline & Group I & Group II & $P$ \\
\hline Sedation & 7 & 7 & NS \\
- before delivery & 6 & 9 & NS \\
- after delivery & & & \\
Nausea or vomiting & & 5 & NS \\
- before delivery & 5 & 4 & NS \\
- after delivery & 7 & & \\
Shivering & & 11 & NS \\
- before delivery & 12 & 3 & NS \\
- after delivery & 8 & & \\
Chest pain & & 7 & NS \\
- before delivery & 3 & 6 & NS \\
\hline - after delivery & 5 & & \\
\hline
\end{tabular}

$\mu \mathrm{g}$ to $2 \%$ lidocaine with 1:200,000 epinephrine while establishing epidural anaesthesia for Caesarean section. Epidural fentanyl was equally effective following delivery when the potential for neonatal exposure to fentanyl was absent.

An initial postulate, that epidural fentanyl would accelerate the onset of epidural blockade with lidocaine, as has been demonstrated with bupivacaine, was not demonstrated. The corollary, that women receiving fentanyl with lidocaine would need less lidocaine, was not supported either. All epidural catheters were at $\mathrm{L}_{2-3}$ in Group II, whereas six of 30 were at $\mathrm{L}_{3-4}$ in Group I (the rest being at $\left.L_{2-3}\right)$. Fentanyl did not speed the onset of blockade to 
TABLE VI Apgar scores and uterine incision to delivery times for infants with Apgar scores 4-6 (all Group II)

\begin{tabular}{lll}
\hline Imin Apgar & $5 \min$ Apgar & UID $(\mathrm{sec})$ \\
\hline 4 & 9 & 152 \\
4 & 9 & 85 \\
4 & 8 & 72 \\
5 & 8 & 52 \\
6 & 8 & 116 \\
6 & 9 & 154 \\
6 & 8 & 195 \\
\hline
\end{tabular}

overcome the more caudal position of the epidural catheters in Group I.

As lidocaine has a faster onset of action than bupivacaine, fentanyl may not enhance the rapid onset of lidocaine epidural blockade. Lidocaine $2 \%$ may be more potent than bupivacaine $0.5 \%$, so that adding fentanyl to lidocaine does not improve the quality of analgesia. Group I pain scores were not different from those of Group II, before or after delivery. Use of supplemental analgesics was not different. Other authors have reported less supplemental medication in women receiving epidural fentanyl than in women receiving only epidural local anaesthetic. ${ }^{3-5}$ A possible explanation why we did not show an advantage in giving epidural fentanyl with lidocaine while establishing epidural anaesthesia is that we used undiluted fentanyl in a small volume $(1.5 \mathrm{ml})$. In other studies the fentanyl was diluted with the local anaesthetic agent. ${ }^{4-6}$ Perhaps the fentanyl was distributed to a larger area because of this dilution. The fentanyl-local anaesthetic combination was also given in larger volume boluses in these studies. However, Gaffud et al. ${ }^{3}$ demonstrated improved intraoperative analgesia using epidural fentanyl undiluted with local anaesthetic. To date, no study has attempted to show the necessity of fentanyl dilution for improvement of analgesia during surgery. It has been shown that, for analgesia after Caesarean section, fentanyl should be used in doses of 50-100 $\mu \mathrm{g}$ and optimally in volumes of $10-20 \mathrm{ml} .{ }^{9}$ This provides the shortest onset with the longest duration of analgesia.

Sedation occurred in about $25 \%$ of patients before and after delivery, and was similar in patients in Groups I and II. Paech noted a similar incidence with bupivacaine and fentanyl. ${ }^{6}$ Significant sedation or respiratory depression was not observed. The incidence of nausea and/or vomiting was similar to that reported by Paech ${ }^{6}$ and lower than reported by Preston $e t$ al..$^{5}$ and Gaffud $e t a l .^{3}$ In women having uterine exteriorization, three of $12(25 \%)$ experienced nausea. This contrasts with Ackerman who has reported that epidural fentanyl reduces the incidence of nausea and/or vomiting from $47 \%$ to $7 \% .^{8}$

Shivering occurred in 26 patients ( $43 \%$ ). The incidence did not differ between groups before or after delivery. The non-invasive blood pressure machine was unable to determine the blood pressures of one patient in each group because of shivering. Thus, epidural fentanyl did not affect the incidence of shivering and this was also reported by Paech. ${ }^{6}$ It is difficult to reconcile this result with reports that fentanyl stopped shaking from epidural anaesthesia in $72 \%$ of patients within 15 min. ${ }^{7}$ A recent report showed a decreased incidence of shivering when fentanyl $25 \mu \mathrm{g}$ was added to $0.5 \%$ bupivacaine. ${ }^{10}$ Some evidence supports using warm iv fluids to decrease shivering, ${ }^{11,12}$ but McCarroll et al. refute this claim. ${ }^{13}$ We used room temperature $i v$ fluid in the hope of maximizing the chance that women would shiver, and to see if fentanyl affected the incidence of shivering. Epidural sufentanil has been reported to stop shivering after epidural anaesthesia. ${ }^{14,15}$ As shivering is often secondary to hypothermia, blunting the shivering response may not be wise. Temperature decreased $0.50 \pm 0.45^{\circ} \mathrm{C}$ in shivering patients and $0.67 \pm$ $0.45^{\circ} \mathrm{C}$ in non-shivering patients. Indeed, sufentanil has caused cessation of shivering and patients have then been observed to decrease their body temperatures to as low as $33^{\circ} \mathrm{C}^{15}$ The aetiology of shivering during epidural anaesthesia remains unclear. ${ }^{16-18}$ The most reasonable approach to avoid shivering may be to maintain body temperature.

Chest pain during epidural anaesthesia can occur at any time during Caesarean section. In this study chest pain occurred as early as before skin incision and up until skin closure. No ECG changes were noted in any patient. The cause of chest pain remains unclear. While some authors think that chest pain may reflect myocardial ischaemia, ${ }^{19}$ clinically important coronary artery disease is very uncommon in young women. Chest pain is often ascribed to "visceral reflex" pain. However, this does not explain the chest pain before skin incision. The presence or absence of epidural fentanyl did not affect the occurrence of chest pain.

Neonatal outcomes as measured by umbilical arterial blood $\mathrm{pH}$ and Apgar scores at one and five minutes were equal in both groups. The lowest Apgar scores occurred in women in Group II, and most were not related to a prolonged uterine incision to delivery time. The reason was probably difficult extraction and/or uteroplacental unit dysfunction before Caesarean section. Epidural fentanyl given to the mother had no detectable effect on the neonate. Other work substantiates this observation. Neonatal neurologic and adaptive capacity scoring (NACS) systems have been reported to be equivalent whether the mother received epidural fentanyl or not. ${ }^{4,5}$ Neonatal breathing patterns were also similar. ${ }^{20,21}$

In summary, maternal and neonatal outcomes were found to be similar whether epidural fentanyl was given 
with lidocaine during induction of epidural anaesthesia, or when it was given after delivery. As it is impossible to "prove" safety, the use of fentanyl before delivery must be justified given the potential for adverse neonatal effects. Others have shown the usefulness of epidural fentanyl as an adjunct to lidocaine and bupivacaine. Since equal benefit is obtained by giving fentanyl after delivery, when the risks of neonatal depression from fentanyl are zero, we suggest that fentanyl be given after delivery of the infant.

\section{References}

1 Carrie LES, O'Sullivan GM, Seegobin R. Epidural fentanyl in labour. Anaesthesia 1981; 36: 965-9.

2 Naulty JS, Datta S, Ostheimer GW, Johnson MD, Burger GA. Epidural fentanyl for postcesarean pain management. Anesthesiology 1985; 63: 694-8.

3 Gaffud MP. Bansal P, Lawton C, Velasquez N, Watson $W A$. Surgical analgesia or cesarean delivery with epidural bupivacaine and fentanyl. Anesthesiology 1986; 65: $331-4$.

4 Tessler MJ, Biehl DR, Naughler MA. Caesarean section with epidural carbonated lidocaine and fentanyl. Can J Anaesth 1988; 35: S110-1.

5 Preston PG, Rosen MA, Hughes SC, et al. Epidural anesthesia with fentanyl and lidocaine for cesarean section: maternal effects and neonatal outcome. Anesthesiology 1988; 68: 938-43.

6 Paech MJ, Westmore MD, Speirs HM. A double-blind comparison of epidural bupivacaine and bupivacainefentanyl for caesarean section. Anaesth Intensive Care 1990; 18: 22-30.

7 Matthews NC, Corser $G$. Epidural fentanyl for shaking in obstetrics. Anaesthesia 1988; 43: 783-5.

8 Ackerman WE, Juneja MM, Colclough GW, Kaczorowski $D M$. Epidural fentanyl significantly decreases nausea and vomiting during uterine manipulation in awake patients undergoing cesarean section. Anesthesiology 1988; 69: A679.

9 Bimbach DJ, Johnson MD, Arcario T, Datta S, Naulty SJ, Ostheimer $G W$. Effect of diluent volume on analgesia produced by epidural fentanyl. Anesth Analg 1989; 68: 808-10.

10 Liu WHD, Luxton MC. The effect of prophylactic fentanyl on shivering in elective caesarean section under epidural analgesia. Anaesthesia 1991; 46: 344-8.

11 Workhoven $M N$. Intravenous fluid temperature, shivering, and the parturient. Anesth Analg 1986; 65: 496-8.

12 Aglio LS, Johnson MD, Datta S, Ostheimer GW. Warm intravenous fluids reduce shivering in parturients receiving epidural analgesia. Anesthesiology 1988; 69: A701.
13 McCarroll SM, Cartwright $P$, Weeks SK, Donati $F$. Warming intravenous fluids and the incidence of shivering during caesarean sections under epidural anaesthesia. Can J Anaesth 1986; 33: S72-3.

14 Johnson $M D$, Sevarino FB, Lema MJ, Datta S, Ostheimer $G W$, Naulty $J S$. Effect of epidural sufentanil on temperature regulation in the parturient. Anesthesiology 1987; 67: A450.

15 Johnson $M D$, Sevarino FB, Lema MJ. Cessation of shivering and hypothermia associated with epidural sufentanil. Anesth Analg 1989; 68: 70-1.

16 Sessler DI, Ponte J. Shivering during epidural anesthesia. Anesthesiology 1990; 72: 816-21.

17 Ponte J, Sessler DI. Extradurals and shivering: effects of cold and warm extradural saline injections in volunteers. Br J Anaesth 1990; 64: 731-3.

18 Imrie MM, Hall GM. Body temperature and anaesthesia. Br J Anaesth 1990; 64: 346-54.

19 Palmer CM, Norris MC, Giudici MC, Leighton BL, DeSimone $C A$. Incidence of electrocardiographic changes during cesarean delivery under regional anesthesia. Anesth Analg 1990; 70: 36-43.

20 Schlesinger TS, Miletich DJ. Epidural fentanyl and lidocaine during cesarean section: maternal efficacy and neonatal safety using impedance monitoring. Anesthesiology 1988; 69: A649.

21 Benlabed $M$, Midgal $M$, Dreizzen E, Escourrou $P$, Ecoffey $C$, Gaultier $C$. Neonatal pattern of breathing after cesarean section with or without epidural fentanyl. Anesthesiology 1988; 69; A651. 